\title{
Female chacma baboons form strong, equitable, and enduring social bonds
}

\author{
Joan B. Silk • Jacinta C. Beehner • Thore J. Bergman • Catherine Crockford • \\ Anne L. Engh • Liza R. Moscovice • Roman M. Wittig • Robert M. Seyfarth • \\ Dorothy L. Cheney
}

Received: 16 November 2009 /Revised: 12 May 2010 /Accepted: 17 May 2010 /Published online: 3 June 2010

(C) The Author(s) 2010. This article is published with open access at Springerlink.com

\begin{abstract}
Analyses of the pattern of associations, social interactions, coalitions, and aggression among chacma baboons (Papio hamadryas ursinus) in the Okavango Delta of Botswana over a 16-year period indicate that adult females form close, equitable, supportive, and enduring social relationships. They show strong and stable preferences for close kin, particularly their own mothers and daughters. Females also form strong attachments to
\end{abstract}

Communicated by A. Widdig

J. B. Silk $(\bowtie)$

Department of Anthropology, University of California,

Los Angeles, CA 90095, USA

e-mail: jsilk@anthro.ucla

J. C. Beehner · T. J. Bergman

Department of Psychology, University of Michigan,

Ann Arbor, MI 48109, USA

J. C. Beehner

Department of Anthropology, University of Michigan,

Ann Arbor, MI 48109, USA

T. J. Bergman

Department of Ecology and Evolutionary Biology,

University of Michigan,

Ann Arbor, MI 48109, USA

C. Crockford $\cdot$ R. M. Wittig

School of Psychology, University of St. Andrews,

St. Andrews KY16 9JP, United Kingdom

A. L. Engh · R. M. Seyfarth

Department of Biology, University of Pennsylvania, Philadelphia, PA 19104, USA

L. R. Moscovice $\cdot$ D. L. Cheney

Department of Psychology, University of Pennsylvania, Philadelphia, PA 19104, USA unrelated females who are close to their own age and who are likely to be paternal half-sisters. Although absolute rates of aggression among kin are as high as rates of aggression among nonkin, females are more tolerant of close relatives than they are of others with whom they have comparable amounts of contact. These findings complement previous work which indicates that the strength of social bonds enhances the fitness of females in this population and support findings about the structure and function of social bonds in other primate groups.

\section{Keywords Baboons $\cdot$ Social bonds $\cdot$ Kinship $\cdot$ Coalitions}

Sociality evolves when the net benefits of association with conspecifics exceed the costs. Individuals that live in social groups may be less vulnerable to predation, better able to defend valued resources, and able to benefit from pooling information, but they must also cope with resource competition from other group members, the threat of infectious diseases, and the risk of infanticide (Krause and Ruxton 2002). These tradeoffs favor the evolution of behavioral strategies that enable individuals to increase the benefits that they gain and minimize the costs that they incur by living in social groups. For primates and other obligately social animals, a growing body of evidence suggests that the formation of strong social bonds may enhance benefit/cost ratios. Female yellow baboons (Papio hamadryas cynocephalus) living in the Amboseli basin of Kenya that are more socially integrated into their groups have higher survivorship among their infants than females who are less socially integrated (Silk et al. 2003a). Similarly, female chacma baboons (Papio hamadryas ursinus) in the Moremi Reserve of the Okvango Delta of Botswana who maintained strong bonds with other adult females had higher survivorship among their offspring than 
females who had weaker bonds with females (Silk et al. 2009). Positive correlations between sociality and reproductive success have also been documented in feral horses (Equus equus; Cameron et al. 2009).

The factors that underlie the correlations between sociality, the formation of strong social bonds, and fitness outcomes are not fully understood, and there is some uncertainty about the direction of the causal links between these behaviors and fitness outcomes. However, a growing body of evidence suggests that sociality affects physiology. When rats (Rattus norvegicus) are housed in isolation, they become hypervigilant and fearful of new stimuli (Cavigelli and McClintock 2003; Cavigelli et al. 2006). Fearfulness early in life is associated with greater reactivity to stressful events later in life and earlier age at death. Socially isolated females have more exaggerated glucocorticoid responses to everyday stressors and are much more likely to develop mammary cancers than group-housed females (McClintock et al. 2005). Prolonged social stress impairs the immune system of male long-tailed macaques (Macaca fascicularis), but affiliative interactions with group members partially offset these deleterious effects (Cohen et al. 1992).

The quality of social relationships may influence females' ability to cope with the challenges of daily life. For example, female house mice (Mus musculus), which often share nests with other females and rear their pups communally, reproduce more successfully when they are allowed to choose their nestmates than when nestmates are assigned randomly (Weidt et al. 2008). Rat sisters with well-balanced affiliative relationships exhibit lower glucocorticoid levels, fewer tumors, and higher survival rates than those with less well-balanced relationships (Yee et al. 2008). Female chacma baboons (P. h. ursinus) in the Okavango Delta of Botswana display marked increases in glucocorticoid levels when a preferred social partner dies (Engh et al. 2006a). In the same population, females with more focused grooming networks show less pronounced responses to various stressors, including the immigration of potentially infanticidal males (Crockford et al. 2008; Wittig et al. 2008).

A different perspective, based on the biological markets approach (Noë and Hammerstein 1994), deemphasizes the importance of long-term social relationships among individuals. This approach posits that, rather than maintaining long-term bonds with specific partners, individuals interact with trading partners who control important commodities that are exchanged over short time periods according to the principles of supply and demand (Barrett et al. 1999, 2003; Fruteau et al. 2009; Henzi and Barrett 2002). Exchanges are based on the current value of commodities and the supply of alternative trading partners.

These two views are not mutually exclusive, because stable, long-term relationships could be initiated, maintained, or both by interactions that are based on the current value of commodities. However, the views differ in their expectations about the stability of relationships. There is considerable evidence supporting the biological markets view that relationships vary with current conditions. Several studies have shown, for example, that female baboons often groom lactating females to obtain immediate access to their infants (Seyfarth 1976; Altmann 1980; Frank and Silk 2009b; Henzi and Barrett 2002; Silk et al. 2003b). Female baboons are particularly likely to reconcile after conflicts with mothers of newborns, as reconciliatory behavior facilitates infant handling (Silk et al. 1996). Further evidence of the malleability of social exchanges comes from studies of chacma baboons at two sites in South Africa. Grooming was relatively well balanced within bouts in groups that had very low levels of aggression but was more skewed in favor of higher-ranking females in groups with higher levels of aggression (Barrett et al. 1999). In addition, seasonal changes alter the patterns of grooming and association within groups (Henzi et al. 2009).

However, recent evidence indicates that, despite shortterm fluctuations in behavior due, for example, to the birth of infants, some animals do form stable and equitable relationships that can endure for years. For example, female baboons in Amboseli form strong, equitable, supportive, and enduring social relationships with selected partners. Females form the strongest social bonds with those that groom them most equitably, and those that groom most equitably have the most enduring social bonds (Silk et al. 2004, 2006a, b). A strikingly similar pattern characterizes male chimpanzees (Pan troglodytes schweinfurthii) in the Kibale Forest of Uganda (Mitani 2009). Indeed, a number of studies have demonstrated that primates balance grooming exchanges with reciprocating partners and that grooming in these dyads is less balanced over short periods than over extended periods of time (chimpanzees: Gomes et al. 2009; capuchins (Cebus apella): Schino et al. 2009, anubis baboons (P. h. anubis): Frank and Silk 2009b). Strong nepotistic biases in patterns of grooming, association, and coalitionary support are also seen in many primate groups (reviewed in Silk 2007, 2009).

Here, we examine the structure and temporal consistency of social relationships among female chacma baboons in the Moremi Reserve. We hypothesized that the similarity in the effects of sociality on reproductive success among female baboons in Amboseli and Moremi would be reflected in corresponding similarities in the structure and stability of social relationships among females at these sites. Thus, we expected females in Moremi to form strong, supportive, equitable, and stable social relationships with selected partners. This hypothesis is supported by a previous work that indicates that female baboons in Moremi share a number of characteristics with East African 
baboons. For example, they establish matrilineal dominance hierarchies, selectively groom maternal kin (Cheney and Seyfarth 2007; Silk et al. 1999), and form alliances with other adult females (Wittig et al. 2007). However, the hypothesis appears to be contradicted by evidence from other sites in South Africa where there seems to be little temporal consistency in female partner choice from month to month within (Henzi et al. 2009) or across years (Barrett and Henzi 2002). Based on these findings, Henzi et al. (2009) have concluded that female baboons do not "sustain relationships with a constant and circumscribed set of individuals over time, but instead form only short-term companionships with an array of different partners in response to local ecological contingencies". Here, we test this conclusion.

\section{Subjects and methods}

\section{Study group}

Analyses focus on the behavior of adult females in one group of free-ranging baboons in the Moremi Game Reserve in the Okavango Delta of Botswana (Cheney and Seyfarth 2007; Cheney et al. 2004). This group was habituated in the late 1970s by William J. Hamilton III and his colleagues, who continued observations of the group into the 1980s. From June 1992 through December 2007 , the group was observed almost daily by a series of researchers working in collaboration with Dorothy Cheney and Robert Seyfarth. During this period, the group averaged 75 individuals (Fig. 1) and the number of adult females in the group averaged 25 .

In the Moremi reserve, grasslands flood annually (usually between May and October), leaving elevated islands edged with woodland. Baboons feed extensively on a number of tree species in these edged woodlands. During floods, baboons ford the submerged plains and move between islands throughout an approximately $5-\mathrm{km}^{2}$ range. The population density of baboons in this area is approximately $24 / \mathrm{km}^{2}$, considerably higher than the densities in other areas where baboons have been studied (Hamilton et al. 1976; unpublished data).

The Moremi baboons live in female-bonded groups. Females remain in their natal group throughout their lives, and males emigrate after attaining sexual maturity at around 9 years of age. When immigrant males enter the group, they may challenge the alpha male, and successful challengers often kill unrelated, unweaned infants (Palombit et al. 2000). Predation is the major cause of mortality for juveniles and adults, while infanticide is the major cause of mortality for infants (Cheney et al. 2004; Cheney and Seyfarth 2007).

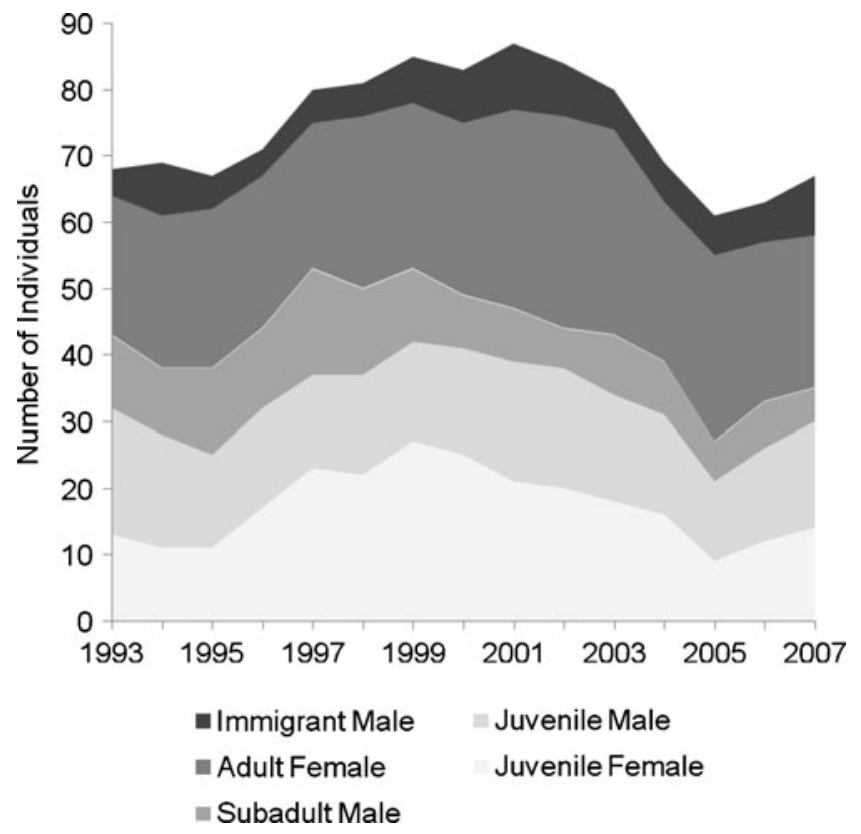

Fig. 1 Demographic composition of the study group. The number of juvenile females, juvenile males, subadult males, adult females, and non-natal adult males in the group on January 1 of each year of the study period is respectively shown. Group size varied from 61 to 85 , and the number of adult females varied from 21 to 32

\section{Assessment of kinship}

Maternal kin relationships among adult females were based on genealogical records. Maternal kinship for all individuals born since 1992 was known with certainty, but gaps in demographic data collection in the 1980s produced some uncertainty about the genealogical relationships among individuals born before this point. The depth of geneaological information for females in our sample varied. For 18 females, we had information about three generations of maternal ancestors (mother, grandmother, and greatgrandmother); for 23 females, we had information about two generations; for 14 females, we had information about one generation; and for seven females (all born before 1982), we had no information about the identity of maternal ancestors.

Paternity was known for a small subset of the adult females in our sample born after 1997, but there were not enough pairs of adult paternal half-sisters to assess the effects of paternal kinship on the strength of social bonds. Instead, we investigated the effects of age proximity on the strength of social bonds, which may serve as a proxy for paternal relatedness (Altmann 1979). In the Moremi population, the highest-ranking male has priority of access to females and achieves the highest mating success (Bulger 1993). Ongoing paternity analyses confirm that there is a high degree of reproductive skew among males in this population (Cheney and Seyfarth, unpublished data). 


\section{Dominance rank}

Dominance ranks among adult females were determined by the direction of approach-retreat interactions among adult females (Silk et al. 1999). Approach-retreat interactions among adult females were tallied each month to produce monthly dominance hierarchies. Females were ordered to minimize the number of entries below the diagonal of the dominance matrix. If there were no interactions within a particular dyad in a given month, their dominance relationship was assumed to have remained unchanged since the previous month.

Based on the monthly ordinal rank order, we computed the proportion of females dominated by each female in that month. This was calculated as: $(N-d) /(N-1)$, where $N$ is the total number of adult females in the group and $d$ is the ordinal rank of a particular female. Thus, the highest-ranking female in the group is ranked 1, while the lowest ranking female is ranked 0 . We computed dominance rank in this way because it allows us to compare the dominance rank of females living in groups of different sizes.

For analyses based on single years, we assigned each female the dominance rank that she held in January of the observation year. Not all females were assigned adult ranks at the same age, so we lack information about the dominance rank of some females when they were 5 to 6 years old. For observations during 1992, we assigned females the ranks that they held during July 1992, the first month of the study. For analyses based on data collected across years, we summed up the females' ranks in January of each year and divided the total by the number of years that they were present and ranked.

As in other baboon populations, females in Moremi formed linear dominance hierarchies with very few reversals. Female dominance ranks generally remained stable over the 16-year period of the study, with daughters assuming ranks similar to those of their mothers (Cheney and Seyfarth 2007; Engh et al. 2009; Silk et al. 1999). Younger sisters have typically risen in rank over older sisters, while ranks between mothers and daughters have not been as predictable. Some mothers have continued to rank higher than their adult daughters, others have dropped below their daughters, as in the Amboseli population (Cheney and Seyfarth, unpublished data; Combes and Altmann 2001). Several members of a middle-ranking matriline dropped to the bottom of the female dominance hierarchy between 2003 and 2004 (Engh et al. 2006b).

\section{Behavioral data collection}

Focal samples were collected by observers in 1992-1993 and 2001-2007 using a common protocol. During these years, all adult females ( $>5$ years of age) were the subjects of regular 10-min focal animal samples. Sampling was usually conducted 6 days a week. Using a handheld computer, observers recorded all approaches, vocalizations, social interactions, and aggressive interactions that were initiated by the focal subject toward another adult or directed by another adult to the focal animal. The onset and termination of all grooming bouts was recorded, producing information about the total amount of time spent grooming.

The dataset is composed of approximately 15,300 focal observations of 66 adult females. There were 1,174 pairs of females who lived in the group at the same time (co-resident dyads, hereafter). For each pair of females, we computed the amount of time that each member of the dyad was observed when the other female was also present (co-residence time, hereafter). Dyads were observed $14.15 \pm 0.22 \mathrm{~h}$ per year and were co-resident for $2.77 \pm 0.05$ years, yielding an average of $47.15 \pm 0.9$ h of observation per dyad across years. Dyads with less than $10 \mathrm{~h}$ of co-residence time across years were excluded from the analyses, leaving a total of 998 dyads. The final sample included 24 mother-daughter pairs, 28 pairs of maternal sisters, two grandmother-granddaughter dyads, 40 aunt-niece pairs, 18 pairs of cousins, six great aunt-niece dyads, and 879 pairs of females that were known not to be related through maternal lines.

\section{Analysis}

We tabulated the total number of approaches, groom initiations, groom presents, greetings and embraces, and agonistic supports (coalitions) between the members of each dyad. Observers recorded the time when each grooming bout began and ended, so we were also able to compute the length of each grooming bout in seconds.

To adjust for variation in co-residence time across dyads, we divided the number of approaches, groom presents, and grooming initiations for each dyad by their co-residence time. These values yielded hourly rates of interaction for each dyad. We divided the total amount of time spent grooming (summed across all grooming bouts) by co-residence time to obtain the amount of grooming per hour for each dyad.

Following Silk et al. (2006a, b), we constructed a composite sociality index (CSI) to characterize affiliative relationships within dyads. To determine what behaviors should be included in the CSI, we evaluated the magnitude of the correlations among all behaviors and retained behaviors that generated the highest correlations: hourly rates of approaches, presents for grooming, grooming initiations, and the number of minutes of grooming per hour.

The CSI was constructed as follows:

$$
\left(A_{i j} / A_{\text {ave }}+P_{i j} / P_{\text {ave }}+G_{i j} / G_{\text {ave }}+D_{i j} / D_{\text {ave }}\right) / 4
$$

The first term represents the hourly rate of approaches for dyad $i, j$ divided by the average hourly rate of approaches for 
all dyads. The second term is based on the hourly rate of presents for grooming, the third is based on hourly rates of grooming initiations, and the last is based on the number of minutes of grooming per hour. These values are summed up and then divided by four. In this population, $A_{\text {ave }}=0.5955 \pm 0.0168$ (mean \pm S.E. acts per hour), $P_{\text {ave }}=0.0279 \pm 0.0018$, and $G_{\text {ave }}=0.0614 \pm 0.0064$; $D_{\text {ave }}=7.8826 \pm 0.8342$ (minutes per hour.)

The CSI measures the extent to which each dyad deviated from other dyads. The mean of the CSI is defined as 1 , but the values can range from 0 to infinity. High values of the CSI represent dyads that had stronger social bonds than the average female dyad in the group, and low values of the sociality index represent dyads that had weaker social bonds.

Some analyses focus on the stability of social relationships across years. For these analyses, we computed separate values of the CSI for each dyad in each year using the same procedures as described above. Again, high values of the annual CSI represent dyads that had stronger affiliative relationships than the average pair of females living in the group in the same year.

Female baboons are strongly attracted to young infants, and the presence of young infants alters the frequency and pattern of interactions among females (Seyfarth 1976; Frank and Silk 2009a; Henzi and Barrett 2002; Silk et al. 2003b). Therefore, we computed two different versions of the CSI for each pair of females. One version was based on observations that were made on days when neither partner had an infant under the age of 100 days. The other version was based on all observations. Analyses based on these two measures generated very similar patterns of results. Analyses of the CSI presented below are based on observations of females on days when they did not have young infants.

Grooming equality Following Silk et al. (2006b), we assessed how evenly grooming was balanced within dyads. For each dyad, we computed how much time (minutes per hour) each female, $i$, spent grooming her partner, $j$, and vice versa. The grooming index is computed as follows:

$1-\operatorname{abs}\left[\left(D_{i j}-D_{j i}\right) /\left(D_{i j}+D_{j i}\right)\right]$

where $D_{i j}$ equals the number of minutes per hour that female $i$ groomed $j$, and $D_{j i}$ equals the number of minutes that female $j$ groomed $i$. The value of the grooming index equals 1 when grooming is evenly balanced within the dyad and 0 when grooming is completely one-sided. We computed separate measures of grooming equality based on all grooming interactions and grooming interactions when neither party had a young infant. Analyses based on both measures yielded very similar results, and the results presented below are based on observations of females on days when they did not have young infants.

Stability of social preferences Following Silk et al. (2006b), we used the yearly values of the CSI to identify each female's top three partners each year. To determine how long close social bonds lasted, we tabulated the consistency in preferred partners across years. If female B was among female A's preferred partners for three consecutive years, then the duration of the close social bond was defined as 3 years. Following Silk et al. (2006b), we allowed a 1-year gap between consecutive years. Thus, if female B was among female A's preferred partners in 2002, 2003, and 2005 , but not 2004 , the duration of the close social bond was defined as 4 years.

There has been some criticism that the decision to allow a 1-year gap between consecutive years artificially inflates the estimates on the duration of social bonds and the prevalence of enduring relationships among females (Henzi and Barrett 2007; Henzi et al. 2009). So, we also measured bond length using a stricter definition, which allowed no gaps between years. The 1-year gap rule and the no-gap rule generated different estimates of bond duration for $1 \%$ of all co-resident dyads and $6 \%$ of all dyads that had close social bonds for at least 1 year. We conducted a parallel set of analyses using the no-gap rule and obtained the same pattern of results in each case.

\section{Statistical analyses}

In the analyses presented below, the dyad is the unit of analysis. The same individuals appear in multiple dyads, so the data points are not independent. General linear mixed models (GLMM) (Baayen 2008) are generally useful for data of this sort, because the identity of individuals can be treated as random-effects parameters.

To examine the source of variation in continuous response variables (CSI, extent of grooming equality, rate of conflict, proportion of conflictual interactions), we first constructed GLMM linear regression models with Gaussian error structure. This regression model assumes that residuals are normally distributed and homogenous. To determine whether the data fit these assumptions, we examined the distribution and homogeneity of residuals for the models based on each of the four continuous response variables. Continuous response variables were square-root-transformed to improve model fit. For each model, the residuals were plotted against the fitted values to determine whether the distribution of the fitted values were similar along the entire range of residual values. We also evaluated the level 1 (dyadic level) and level 2 (individual level) residuals to determine whether they were normally distributed. For these three models, we also 


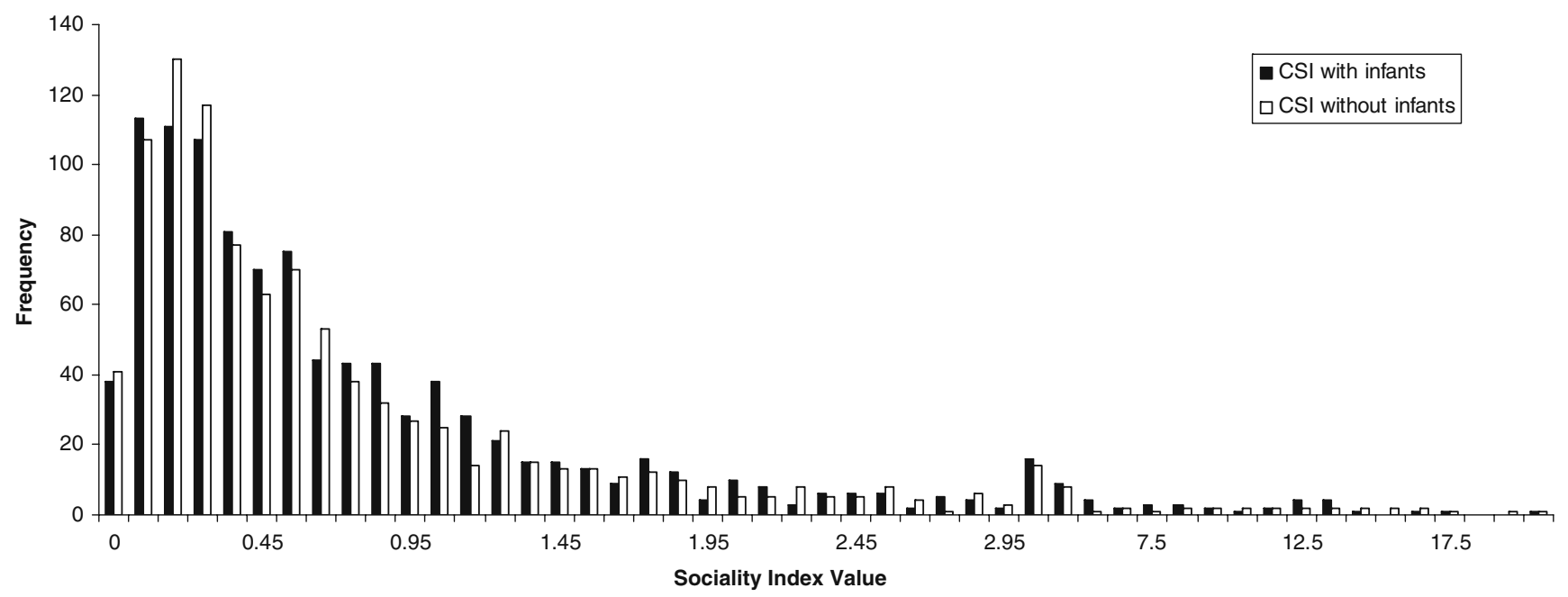

Fig. 2 Distribution of composite sociality index values. The J-shaped distribution indicates that most pairs of females interacted at relatively low rates and had low CSI values, while a small number of dyads interacted at particularly high rates and had high CSI values. White

determined that the level 1 (dyadic level) and level 2 (individual level) residuals fell reasonably close to a normal distribution. We bootstrapped each of these three models with 2,000 repetitions to verify that the confidence intervals for parameter estimates of significant predictor variables did not include zero. The dyad was the unit of analysis in these models.

For models of three of the four continuous response variables (CSI, conflict rate, proportion of conflictual interactions), we detected no strong evidence of deviations from homogeneity or normality and report the results of the GLMM analyses. For the fourth response variable, the degree of grooming equality, we found substantial violations of distributional assumptions. For this response variable, we rely on the bootstrap analyses to assess whether confidence intervals for parameter estimates of predictor variables include zero.

For post hoc analyses of the significance of differences between categories of maternal kin, between peers and nonpeers, and between females that held adjacent and nonadjacent ranks, we used the following procedure. First, we constructed a linear mixed model with crossed effects. The predictor variable was treated as a categorical variable in the model. The crossed effects model the effects of the bars are based on data collected when females did not have young infants. Black bars are based on all data collected. All analyses reported here were based on data collected when females did not have young infants

identity of each member of the dyad. The models for each of the predictor variables were significant, and then we did pairwise comparisons of the means in each category.

Preliminary analyses indicated that relatedness had nonlinear effects on the value of some of the response variables, such as the value of the CSI; in these cases, quadratic terms were added to the model. The values of these variables were centered around the mean to reduce collinearity between the linear and quadratic terms.

To examine the factors that influenced the duration of social bonds, a count variable, we used a GLMM Poisson regression model. In the Poisson regression, the number of years of co-residence is treated as an exposure, and the identities of dyad members were treated as random effects. We tested the dispersion of the data and obtained a non-significant result $(p=0.059)$. The nested model indicated that there was very little variation across individuals, so we conducted two additional regressions without fixed effects, a simple Poisson regression and a negative binomial regression. All of these tests generated very similar coefficients and significance levels for the predictor variables. We therefore report here the results of the GLMM Poisson regression without random effects.
Table 1 Sources of variation in the strength of social bonds

\begin{tabular}{lcrrr}
\hline Predictor variable & Coefficient & S.E. & $z$ & \multicolumn{1}{c}{$p$} \\
\hline Degree of relatedness & 0.8645 & 0.4985 & 1.73 & 0.083 \\
Degree of relatedness squared & 8.1300 & 1.2184 & 6.67 & $<0.001$ \\
Age difference & -0.0294 & 0.0068 & -4.32 & $<0.001$ \\
Rank distance & -0.6779 & 0.1162 & -5.83 & $<0.001$ \\
Age difference $\times$ rank distance & 0.0393 & 0.1578 & 2.49 & 0.013 \\
\hline
\end{tabular}



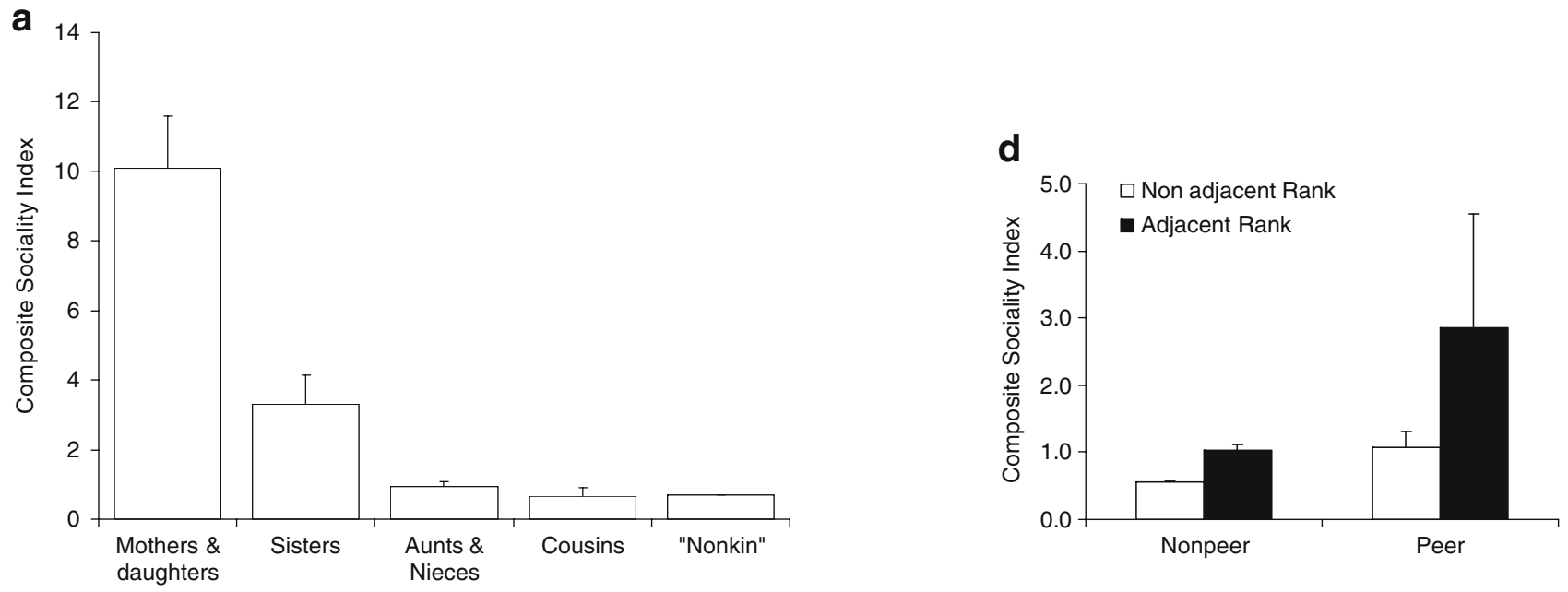

b

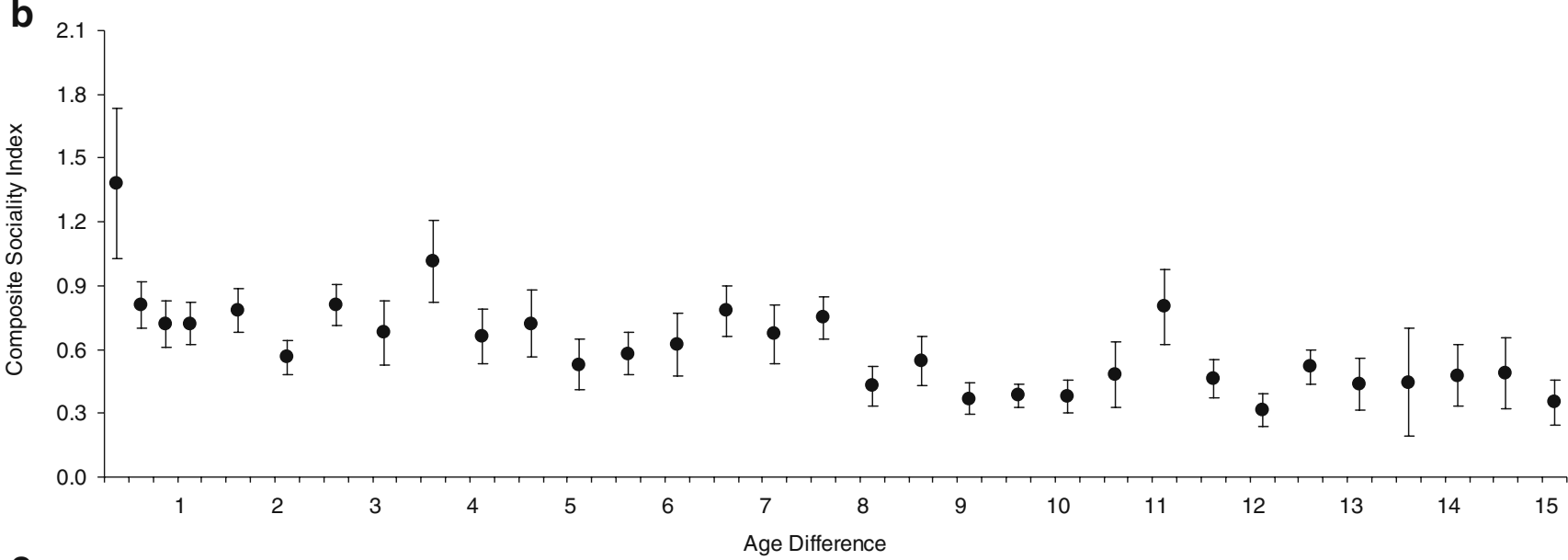

C

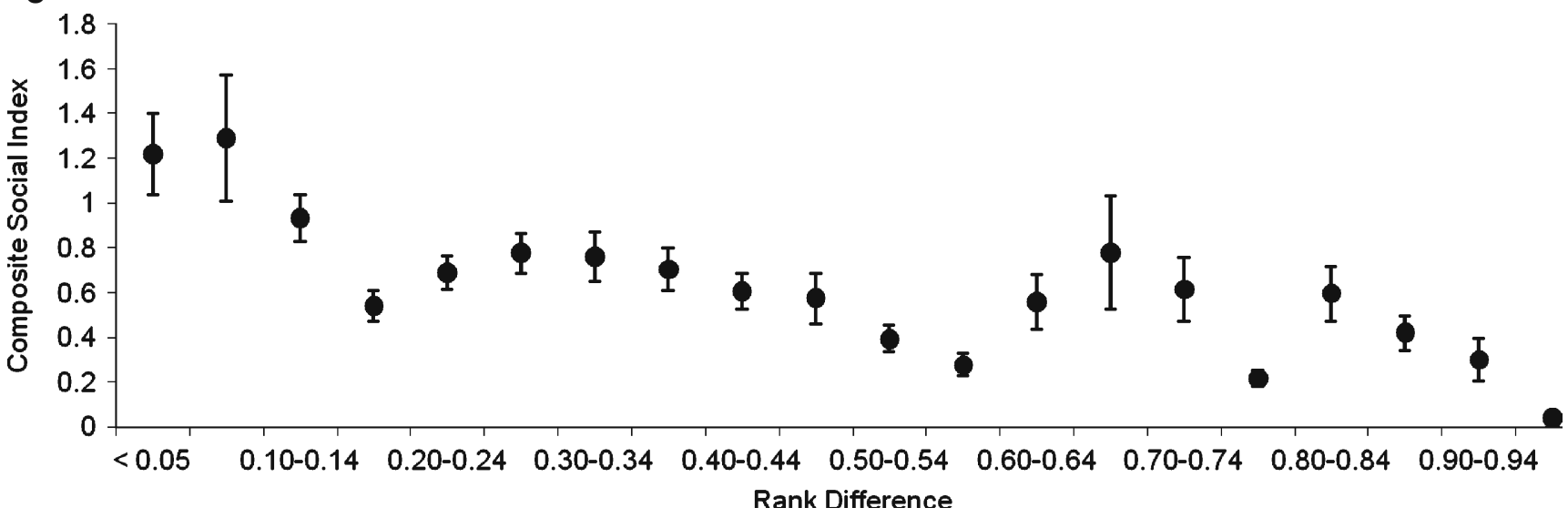

Fig. 3 Sources of variation in values of the composite sociality index. a Effects of maternal kinship. Mothers and daughters had significantly higher CSI values than maternal sisters, and maternal sisters had significantly higher CSI values than aunts and nieces. Values of the CSI for aunts and nieces, cousins, and nonkin could not be distinguished. b Effects of age differences. For unrelated females that were less than 1 year apart in age, dyads are divided into four groups: 0-3 months apart, 3-6 months, 6-9 months, 9-12 months. Females who were less than 3 months apart in age had substantially higher values of CSI than females further apart in age. c Effects of rank differences. Unrelated females with rank differences of less than 0.15 had higher CSI values than females with more disparate ranks. d Joint effects of age proximity and rank distance. Pairs of unrelated females who were peers (within 3 months of age) and held adjacent ranks (dominance rank difference $\leq 0.15$ ) had substantially stronger higher CSIs than other pairs of unrelated female (adjacent/peer: $n=8$; dyads; adjacent/nonpeer: $n=164$; nonadjacent/nonpeer: $n=669$; adjacent/ nonpeer: $n=38$ ) 
Table 2 Post hoc tests of differences in value of CSI among kinship categories

$z$ values are given in the first line of each cell; $p$ values are given in the second line

\begin{tabular}{lllll}
\hline & Sisters & Aunts and nieces & Cousins & Nonkin \\
\hline Mothers and daughters & 11.1 & 17.2 & 15.2 & 23.4 \\
& $<0.001$ & $<0.001$ & $<0.001$ & $<0.001$ \\
Sisters & - & 5.88 & 5.70 & 9.28 \\
& & $<0.001$ & $<0.001$ & $<0.001$ \\
Aunts and nieces & - & 1.07 & 2.24 \\
& & & 0.286 & 0.025 \\
Cousins & & - & 0.30 \\
& & & 0.767 \\
\hline
\end{tabular}

All statistical analyses were conducted with STATA 11.0 (Statcorp 2009).

In the regression analyses, we examined the effects of three predictor variables: degree of maternal relatedness, age difference, and rank distance. For maternal kinship, we used the average degree of relatedness for kin categories (mothers and daughters, $r=0.5$, maternal sisters: $r=0.25$, grandmother and granddaughters, $r=0.25$; aunts and nieces, $r=0.125$; cousins: $r=0.0625$; great-aunts and nieces, $r=$ 0.0625 ; nonkin, all others: $r=0$ ). Note that larger degrees of relatedness correspond to close kin relationships. Age difference was computed as the number of days between the birth of female $i$ and female $j$ divided by 365; this value was always positive. Rank distance was computed as the absolute difference between the proportion of females dominated by female $i$ and the proportion of females dominated by female $j$.

Where appropriate, we report means \pm standard errors. Two-tailed tests of significance were used throughout.

\section{Results}

Sources of variation in the strength of social bonds

The CSI assesses the strength of affiliative social bonds within dyads. The J-shaped distribution of the values of the CSI indicates that many dyads formed very weak social bonds, while a much smaller number of dyads formed very strong bonds (Fig. 2). By definition, the mean value of the CSI was 1.0. The median value of the CSI was 0.45 , and approximately $10 \%$ of the values were greater than 2.0 .

Pairs of females who were more closely related, closer in age, and closer in rank had significantly stronger social bonds than other females (Wald $x^{2}=696.47, p<0.0001, n=$
975 dyads; Table 1). The significance of the squared relatedness term reflects the fact that mothers and daughters formed exceptionally strong social bonds. The mean value of the CSI for mothers and daughters was three times higher than the mean value for maternal sisters and nearly 15 times higher than the mean for pairs of unrelated females (Fig. 3a). Post hoc tests (Table 2) indicate that mothers and daughters had significantly stronger social bonds than any other category of dyads; sisters had significantly stronger social bonds than aunts and nieces, cousins, or unrelated females; aunts and nieces could not be differentiated from cousins but had significantly stronger social bonds than nonkin; cousins and nonkin did not differ significantly.

Females also interacted at significantly higher rates with females who were close to themselves in age (Table 1). Females behaved differently toward unrelated females who were born within 3 months of their own birth and other unrelated females further apart in age (Fig. 3b). Post hoc tests revealed that this difference was statistically significant $(z=-3.36, p=0.001)$. Below, we refer to pairs of females who were born less than 90 days apart as "peers" and females who were born more than 90 days apart as "nonpeers."

Females also interacted at significantly higher rates with females who were close to themselves in dominance rank, and this effect was independent of the effects of kinship (Table 1). Females behaved differently toward unrelated females whose ranks were very close to their own (differed by $\leq 0.15$ ) and females whose ranks were more disparate (Fig. 3c; $z=-6.62, p=0.001$ ). Below, we refer to females with a rank difference $\leq 0.15$ as "rank-adjacent".

Figure $3 d$ illustrates the joint effects of being close in rank and close in age on the strength of social bonds, which is reflected in the significant interaction between age difference and rank distance. The mean value of the CSI
Table 3 Bootstrap analyses of variation in the extent of grooming equality

\begin{tabular}{lrlrrrr}
\hline Predictor variable & Coefficient & S.E. & \multicolumn{1}{l}{$z$} & \multicolumn{2}{c}{$95 \% \mathrm{CI}$} \\
\hline Degree of relatedness & 0.9460 & 0.1367 & 6.92 & $<0.001$ & 0.6781 & 1.2140 \\
Age difference & -0.0123 & 0.0058 & -2.12 & 0.034 & -0.0237 & -0.0009 \\
Rank distance & -0.1490 & 0.0990 & -1.51 & 0.132 & -0.3429 & 0.0450 \\
\hline
\end{tabular}




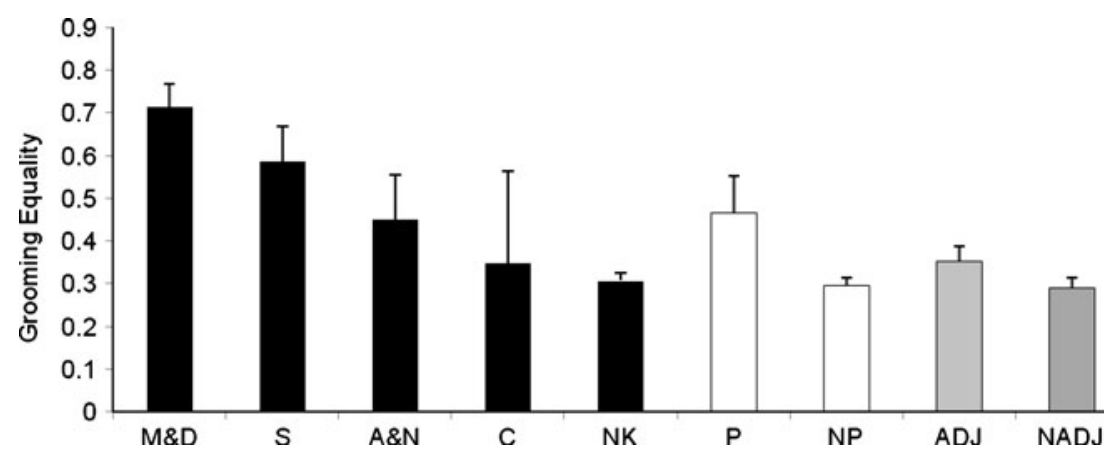

Fig. 4 Sources of variation in grooming equality. The extent of grooming equality ranges from 0 for dyads in which one female was responsible for all of the grooming to 1.0 for dyads in which grooming was perfectly balanced within. Black bars represent mean (and standard error) of values for dyads composed of different categories

for rank-adjacent peers $(2.85 \pm 1.70, n=8)$ was almost as high as the CSI among maternal sisters $(3.31 \pm 0.81, n=28)$.

\section{Grooming equality}

We were able to measure the extent of grooming equality for 421 dyads that groomed during focal samples. There was a considerable variation in the extent of grooming equality across dyads. In $44 \%$ of the dyads that groomed during focal samples, one female was responsible for all of the grooming, but both females contributed to grooming in the remaining dyads. Females groomed close kin and agemates significantly more equitably than they groomed other females, but rank distance had no significant effect on grooming equality (Table 3; Fig. 4).

\section{Conflict and cooperation}

The value of close social bonds may be linked to the need for allies in coalitionary aggression. In Moremi, the overall rate of coalitionary support among females during focal samples was low, but it was not absent altogether $(0.13$ acts per $100 \mathrm{~h}$ versus 16.77 acts of aggression per $100 \mathrm{~h}$ ), nor did rates of support differ substantially from those found in other Old World monkey species (Wittig et al. 2007). In the sample of coalitionary events that we recorded during focal samples $(n=60)$, females preferentially supported close relatives (mothers, daughters, and sisters) and unrelated peers (Fig. 5). Similar results have been obtained from analyses that included a larger sample derived from ad libitum data (Wittig et al. 2007).

Pairs of females who were closely related, close in age, and closely ranked had significantly higher rates of conflict than other females (Wald $x^{2}=113.12, p<0.0001, n=975$; Table 4). The significance of the squared relatedness term reflects the fact that mothers and daughters had considerably lower rates of conflict than other dyads (Fig. 6a). of maternal kin (mothers and daughters $=M \& D$, sisters $=S$, aunts and nieces $=A \& N$, cousins $=C$, nonkin $=N K)$; white bars are based on dyads composed of unrelated peers $(P)$ and nonpeers $(N P)$; gray bars are based on dyads composed of unrelated females who held adjacent $(A D J)$ or nonadjacent $(N A D J)$ ranks

We also computed the proportion of agonistic interactions within each dyad by dividing the rate of conflict by the sum of the rates of conflict and the rates of various forms of affiliative interactions (approaches, grunts, presents for grooming, grooming initiations, coalitionary support, greetings, and embraces). As the degree of relatedness increased, the proportion of agonistic interactions among females steadily declined (Wald $x^{2}=82.19, p<0.0001, n=962$; Table 5; Fig. 6b). Pairs of females who were close in rank had higher proportions of agonistic interactions than pairs who were more distantly ranked, when the effects of relatedness and age distance were held constant. However, age proximity was unrelated to the proportion of agonistic interactions among females.

\section{Stability of social preferences}

The opportunity to maintain close social bonds across years was limited by the length of time that adult females lived together in the group. Fifty percent of the dyads were co-resident for at least 3 years during this period, and $18 \%$ were co-resident for at least 5 years.

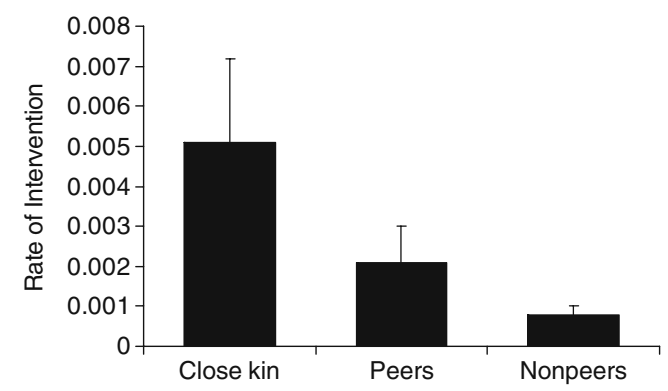

Fig. 5 Distribution of coalitionary support. Close maternal kin (mothers, daughters, and sisters) intervened at higher rates than unrelated peers or unrelated nonpeers. Peers also intervened at higher rates than unrelated nonpeers. Black bars represent mean (and standard error) of values for dyads composed of close kin (mothers, daughters, and sisters), peers, and nonpeers 
Table 4 Sources of variation in the rate of conflict

\begin{tabular}{lcrrr}
\hline Predictor variable & Coefficient & S.E. & $z$ & \multicolumn{1}{c}{$p$} \\
\hline Degree of relatedness & 0.2715 & 0.1372 & 1.98 & 0.048 \\
Degree of relatedness squared & -0.9015 & 0.3347 & -2.69 & 0.007 \\
Age difference & -0.1885 & 0.0210 & -8.99 & $<0.001$ \\
Rank distance & -0.0380 & 0.0011 & -3.47 & $<0.001$ \\
\hline
\end{tabular}

We investigated the factors that influenced the probability that close social bonds would be sustained from 1 year to the next. Females had more enduring preferences for close relatives than distant relatives or nonrelatives (likelihood ratio $x^{2}=207.28, p<0.0001, p=795$; Table 6; Fig. 7). Females also formed significantly longer-lasting relationships with unrelated females who were close to their own ages than females who were much older or younger than themselves, but bond duration was not consistently linked to rank differences among unrelated females.

\section{Discussion}

Female chacma baboons in Moremi form close, equitable, supportive, and enduring social relationships and show strong and stable preferences for close kin and for unrelated females who are close in age and rank. These findings confirm our hypothesis that, in both Amboseli and Moremi, similarity in the effects of sociality would produce corresponding similarities in the structure and stability of social relationships. Further, they complement recent findings demonstrating that both male and female chimpanzees form lasting, well-differentiated relationships with same-sexed partners (Langergraber et al. 2009; Mitani 2009).

Although close kinship clearly enhances the rates of affiliation and support, the effects of kinship on conflict are more complex. A number of studies have shown that rates of aggression are as high among kin as among nonkin (Bernstein 1988; Bernstein et al. 1993). We found the same pattern in our data. In fact, sisters had relatively high levels of conflict compared to mothers and daughters or unrelated females. At the same time, however, the proportion of hostile interactions declined as maternal relatedness increased. These results indicate that females are more tolerant of close relatives than they are of others.

In Moremi and Amboseli, females' relationships with peers were similar in many ways to their relationships with close kin. Females formed stronger bonds with unrelated females who were close to their own age than with females who were further from their own age. In addition, close kinship and age proximity were both linked to grooming
Fig. 6 Distribution of conflict. a Sources of variation in the rate of aggression. Rates of aggression were not significantly related to maternal kinship, although sisters had significantly higher rates of aggression than mothers and daughters or pairs of unrelated females. Black bars represent mean (and standard error) of values for dyads composed of different categories of maternal kin (mothers and daughters $=M \& D$, sisters $=S$, aunts and nieces $=A \& N$, cousins $=C$, nonkin $=N K$ ); white bars are based on dyads composed of unrelated peers $(P)$ and nonpeers $(N P)$; gray bars are based on dyads composed of unrelated females who held adjacent $(A D J)$ or nonadjacent $(N A D J)$ ranks. b Proportion of conflictual interactions. The proportion of interactions that are conflictual declines as maternal relatedness increases.

Conventions as in $\mathbf{a}$
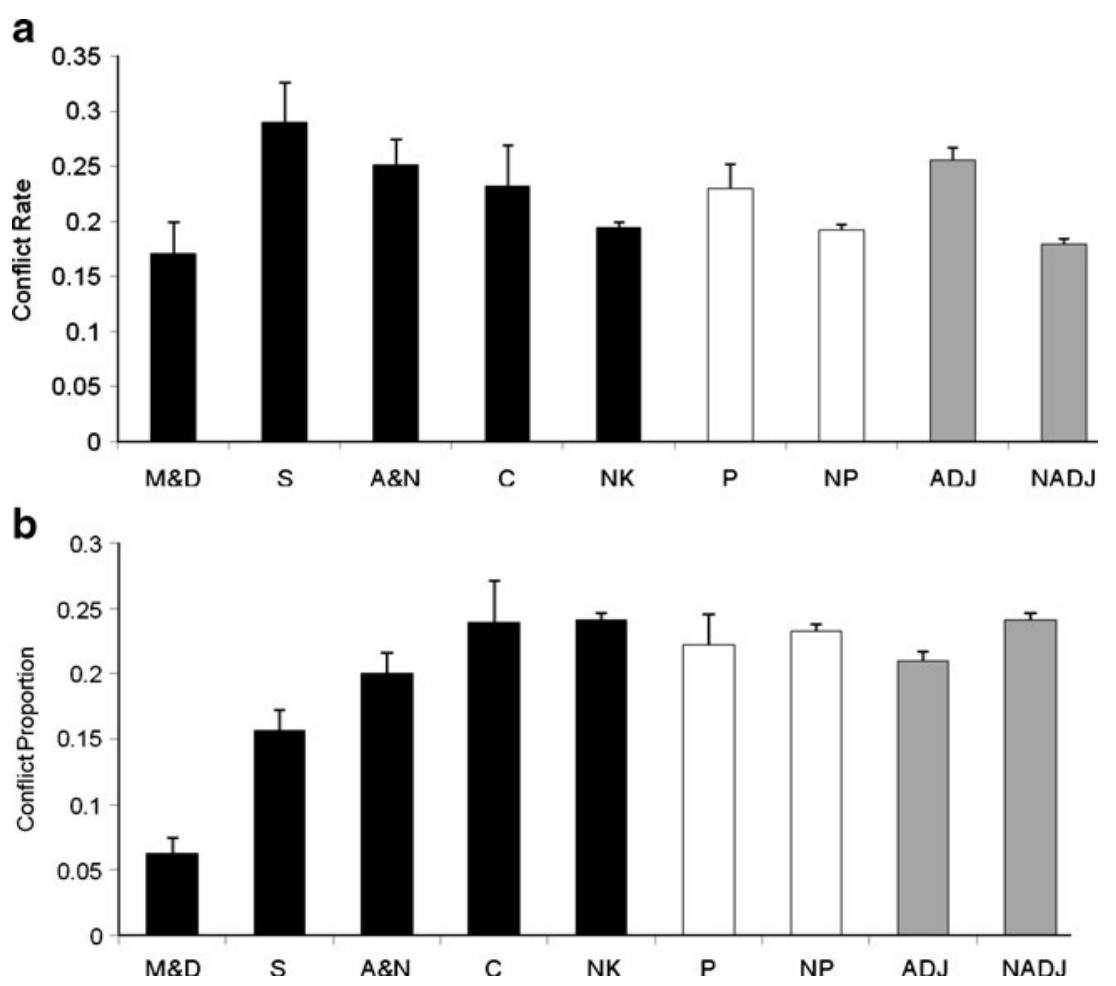
Table 5 Sources of variation in the proportion of conflictual interactions

\begin{tabular}{lrrrr}
\hline Predictor variable & Coefficient & S.E. & \multicolumn{1}{l}{$z$} & \multicolumn{1}{l}{$p$} \\
\hline Degree of relatedness & -0.4848 & 0.0551 & -8.81 & $<0.001$ \\
Age difference & -0.0014 & -0.0012 & -1.10 & 0.270 \\
Rank distance & -0.0485 & 0.0233 & -2.08 & 0.037 \\
\hline
\end{tabular}

equality and the stability of social bonds over time. However, age distance among females did not seem to influence the extent of tolerance among them. Females may have preferred peers because age proximity is a reliable cue of paternal kinship in Moremi.

Females in Moremi made categorical distinctions between females who were within 3 months of their own age and those who were further from their own age. Their preferences may reflect the temporal distribution of births in this population. Although baboons are typically not seasonal breeders (Alberts et al. 2005), approximately three quarters of all births in Moremi occur during a 6-month period between July and December (Cheney et al. 2004). This creates well-defined birth cohorts, in which the maximum age difference between infants is about 6 months. Membership in the same birth cohort may be a good cue of paternal kinship because topranking males monopolize access to females in this population (Bulger 1993) and sire the majority of infants (Cheney and Seyfarth, unpublished data). At the same time, top-ranking males have relatively short tenures (Palombit et al. 2000) and are unlikely to monopolize matings in two successive seasons. In Amboseli, births are distributed more evenly throughout the year (Alberts et al. 2005), and females did not seem to make such clear categorical distinctions based on age proximity (Silk et al. 2006a). The proximate cues that motivate these bonds may derive from the friendships that mothers with new infants form with resident males in an apparent response against the threat of infanticide (Palombit et al. 1997; Moscovice et al. 2010). When lactating females form friendships with the same male, their infants interact at high rates from an early age. These bonds may persist once the male-female friendship ends.

In Moremi and Amboseli, females form stronger social ties with unrelated females who hold adjacent ranks than with females who hold more disparate ranks, but the character of relationships among females who are close in ranks differs from the character of relationships among close kin and peers in several ways. First, rank distance did not affect the extent of grooming equality or the duration of social bonds among unrelated females as it did among close kin and peers. Second, females who were closely ranked were more likely to be involved in conflicts than expected based on their amount of contact, while close kin showed the opposite pattern and peers did not differ from expectations. Third, rank distance did not affect the duration of close social bonds, as kinship and age proximity did. This suggests that the forces shaping social relationships among females who hold adjacent ranks are different than the forces shaping social relationships among close kin and peers. Seyfarth (1976) originally predicted that elevated rates of affiliation among closely ranked females might be the end-product of competition for access to powerful highranking females who trade grooming for support in conflicts. Coalitionary support among unrelated females occurs in Moremi at rates comparable to those found among other cercopithecine primates and it may be important to cultivate relationships with potentially useful partners. Alternatively, our data indicate that females who are closely ranked have particularly competitive relationships. If conflict is followed by reconciliatory gestures, like grunting and grooming (Aureli and de Waal 2000; Cheney and Seyfarth 2007), we would expect there to be a positive correlation between the amount of aggression and the value of the CSI among unrelated dyads, as there is in our dataset.

The same factors that influence the strength of social bonds within dyads also influence the extent of equity in grooming relationships. Similar patterns characterize female baboons in Amboseli and male chimpanzees at Ngogo (Mitani 2009). We do not know whether bond strength promotes the development of balanced grooming relationships within dyads over time or if baboons and chimpanzees preferentially invest in long-term relationships with partners who groom them equitably. However, the linkage between these variables suggests that contingent reciprocity plays an important role in the development and maintenance of social bonds in primate groups. Several recent studies have shown that grooming is more evenly balanced across multiple bouts than within bouts (references above). These studies imply that primates are tolerant of temporary imbalances in services given and received and are able to keep track of the balance of help given and received
Table 6 Sources of variation in the stability of social preferences

\begin{tabular}{lrrrr}
\hline Predictor variable & Coefficient & S.E. & \multicolumn{1}{c}{$z$} \\
\hline Degree of relatedness & 8.4030 & 1.3364 & 6.29 & $<0.001$ \\
Degree of relatedness squared & -5.4333 & 2.7632 & -1.97 & 0.049 \\
Age difference & -0.0698 & 0.0193 & -3.62 & $<0.001$ \\
Rank distance & 0.1124 & 0.3043 & 0.37 & 0.712 \\
\hline
\end{tabular}



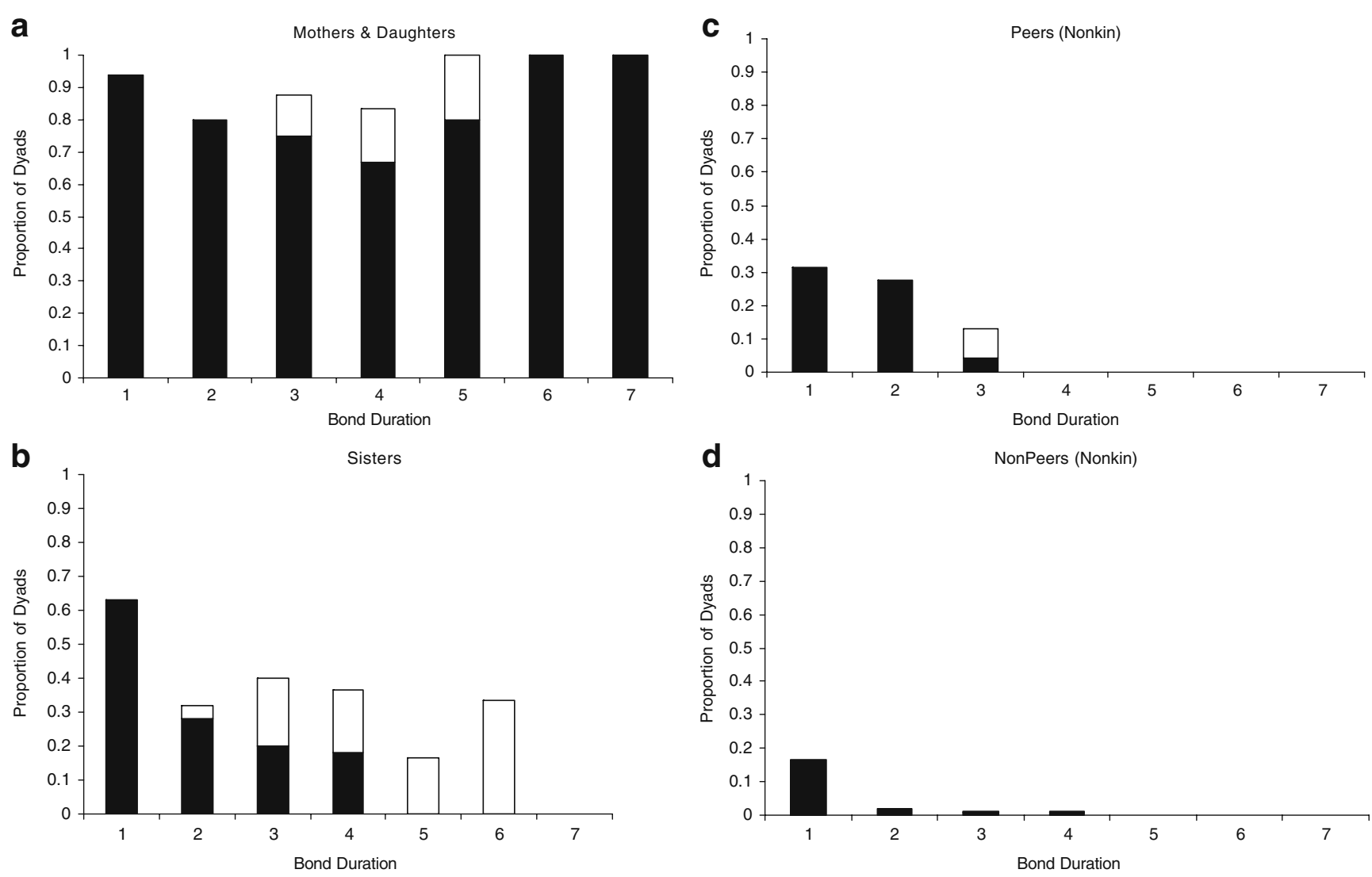

d

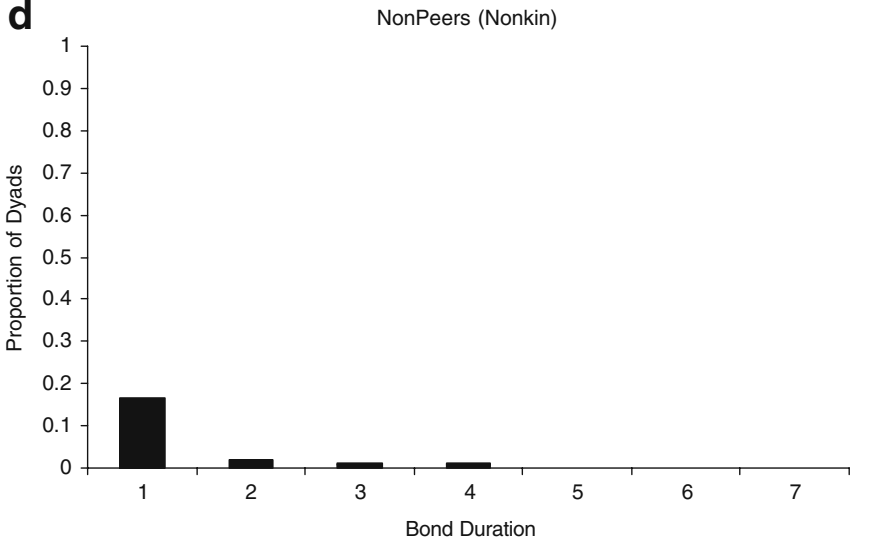

Fig. 7 Bond duration. The likelihood that dyads would sustain close social bonds for a given period of time is plotted for a mothers and daughters, b maternal sisters, c unrelated peers, and d unrelated nonpeers. To obtain these values, we divided the number of dyads that maintained social bonds for at least one, two, or more years by the total number of dyads that were co-resident for at least that long. The white bars represent values of bond duration using the 1-year-gap rule, while the black bars represent values of bond duration using the no-gap rule.

over substantial periods of time. Indeed, meta-analyses have revealed a weak but highly significant correlation between grooming and alliance support among female non-human primates over long time periods (Schino 2007a, b; Shino and Aureli 2007), suggesting that these behaviors have evolved as a system of low-cost contingent cooperation in some species (Shino and Aureli 2007).

The characterization of the nature of social bonds among female baboons in Moremi (this study) and Amboseli (Silk et al. 2006a, b) clearly differs from the characterization of social bonds among females at De Hoop and the Drakensburg Mountains of South Africa (Barrett and Henzi 2002; Henzi and Barrett 2007; Henzi et al. 2009). It is very difficult to make quantitative comparisons between populations because different methods have been used to collect data and analyze the patterns of behavior across sites. For example, our data derived from focal animal samples, while analyses from de Hoop (Barrett and Henzi 2002; Henzi et al. 2009) are based on scan samples of

For example, a shows that $80 \%$ of the mother-daughter pairs that were co-resident for at least 5 years maintained close social bonds for 5 years, using the conservative no-gap rule (black bar); an additional 20\% of the mother-daughter pairs that were co-resident for at least 5 years maintained close social bonds for 5 years using the 1-year gap rule (white bar). Thus, the size of the white bars represents the difference in estimates of bond duration using the 1-year gap rule and the no-gap rule. Statistical results using the two rules generate identical results

nearest neighbors at 30-min intervals. However, some limited comparisons based on published work can be made. In Moremi, females groomed on average at 7.88 min per hour or approximately $13 \%$ of total observation time. In De Hoop, females spent 14\% of their time grooming (Barrett et al. 2002), and in the Drakensburg mountains females spent $8-12 \%$ of their time grooming (Barrett et al. 2002). Thus, female chacma baboons seem to devote similar proportions of time to grooming across sites.

We can also make some rough comparisons of the consistency in female partner choice across time. Barrett and Henzi (2002) used data from scan samples to identify top grooming partners and top associates (nearest neighbors) for nine adult females who were present in the group for four consecutive years. We used this information to tabulate the number of different individuals that were among each females' top grooming partners and top associates over this 4-year period. One female had the same top grooming partner 
over all 4 years, four females had two different partners, three females had three different top partners, and one female had a different top partner in each year. To compare data from de Hoop with data from Moremi, we created an index of the consistency of top partner choice: $Y-U / Y-1$, where $Y=$ the number of years over which partner choice is measured and $U=$ the number of different individuals that were top partners. This index ranges from 1 when females have the same top partner across years to 0 when females have different top partners each year. The average proportion of unique grooming partners for the nine females in the De Hoop group was $0.52 \pm 0.10$ (range, $0-1$ ). The average proportion of unique associates was $0.33 \pm 0.08$ (range, $0-0.67$ ), suggesting that grooming partnerships are somewhat more consistent than associations based on nearest neighbor data.

We replicated these analyses with our data using CSI values that combine information about grooming and proximity (based on approaches). The average value of the index was $0.43 \pm 0.06$ (range, $0-1 ; n=44$ ), a value that is intermediate between the values for grooming and associations in De Hoop.

These findings suggest that the differences in the nature of social relationships among females across sites may not be as great as has been suggested. In Moremi, Amboseli, and de Hoop, some dyads form strong and long-lasting bonds, but other dyads form weaker and more transient relationships. It is possible that market forces shape the dynamics of short-term relationships as females use strategic tactics to gain access to valued resources, including infants (Henzi and Barrett 2002, 2007). As noted earlier, however, hypotheses based on market forces and those based on the maintenance of long-term bonds are not mutually exclusive, since either mechanism could lead to stable, long-term relationships. Moreover, kin selection and contingent reciprocity may also favor the development of long-lasting relationships among some pairs of females, particularly close kin and peers.

It would be fruitful to extend these kinds of comparisons so we can quantify the differences (and similarities) among populations with more precision. This would enable us to assess the possible sources of variation between populations, and to provide a more complete understanding of the genetic, ecological, demographic, and selective forces that shape female social strategies.

Acknowledgements We thank the Office of the President and the Department of Wildlife and National Parks of the Republic of Botswana for the permission to conduct research in the Moremi Reserve. A. Mokopi, M. Mokopi, M. Heesen, C. Shaw, W. Smith, and E. Wikberg provided valuable help with data collection and logistics in the field. J. Fischer, S. Johnson, D. Kitchen, R. Palombit, and D. Rendall contributed to the long-term records. Field research was supported by grants to D.L.C and R.M.S. from the National Geographic Foundation, the Research Foundation of the University of Pennsylvania, the Institute for Research in Cognitive Science at the
University of Pennsylvania, and the National Institute of Health (HD29433; MH62249); to J.B.S. from the National Science Foundation (9213586); to T.M.B. from the National Institutes of Health (NRSA fellowship F32 MH064232); and to R.M.W. from the German Science Foundation (WI 2637/2-1). We thank the reviewers for particularly helpful comments and suggestions.

Open Access This article is distributed under the terms of the Creative Commons Attribution Noncommercial License which permits any noncommercial use, distribution, and reproduction in any medium, provided the original author(s) and source are credited.

\section{References}

Alberts SC, Hollister-Smith J, Mututua RS, Sayialel SN, Muruthi PM, Warutere JK, Altmann J (2005) Seasonality and long-term change in a savanna environment. In: Brockman DK, van Schaik CP (eds) Seasonality in primates: studies of living and extinct human and nonhuman primates. Cambridge University Press, Cambridge, pp 157-196

Altmann J (1974) Observational study of behavior: sampling methods. Behaviour 49:229-267

Altmann J (1979) Age cohorts as paternal sibships. Behav Ecol Sociobiol 6:161-164

Altmann J (1980) Baboon mothers and infants. Harvard University Press, Cambridge

Aureli F, de Waal FBM (2000) Why natural conflict resolution? In: Aureli F, de Waal FBM (eds) Natural conflict resolution. University of California Press, Berkeley, pp 3-10

Baayen RH (2008) Analyzing linguistic data. A practical introduction to statistics. Cambridge University Press, Cambridge

Barrett L, Henzi SP (2002) Constraints on relationship formation among female primates. Behaviour 139:263-289

Barrett L, Henzi S, Weingrill A, Lycett JE, Hill RA (1999) Market forces predict grooming reciprocity among female baboons. Biol Sci 266:665-670

Barrett L, Gaynor D, Henzi SP (2002) A dynamic exchange between aggression and grooming reciprocity among female chacma baboons. Anim Behav 63:1047-1053

Barton RA, Byrne RW, Whiten A (1996) Ecology, feeding competition and social structure in baboons. Behav Ecol Sociobiol 38:321-329

Bernstein IS (1988) Kinship and behavior in nonhuman-primates. Behav Genet 18:511-524

Bernstein IS, Ehardt CL (1985) Agonistic aiding: kinship, rank, age and sex influences. Am J Primatol 8:37-52

Bernstein IS, Judge PG, Ruehlmann TE (1993) Kinship, association, and social relationships in rhesus monkeys (Macaca mulatta). Am J Primatol 31:41-53

Bulger JB (1993) Dominance rank and access to estrous females in male savanna baboons. Behaviour 127:67-103

Bulger JB, Hamilton WJ (1987) Rank and density correlates of inclusive fitness measures in a natural chacma baboon (Papio ursinus) population. Int J Primatol 8:635-650

Cameron EZ, Setsaas TH, Linklater WL (2009) Social bonds between unrelated females increase reproductive success in feral horses. Proc Natl Acad Sci USA 106:13850-13853

Cavigelli SA, McClintock MK (2003) Fear of novelty in infant rats predicts adult corticosterone dynamics and an early death. Proc Natl Acad Sci USA 100:16131-16136

Cavigelli SA, Yee JR, McClintock MK (2006) Infant temperament predicts life span in female rats that develop spontaneous tumors. Horm Behav 50:454-462

Cheney DL, Seyfarth RM (1990) How monkeys see the world. University of Chicago Press, Chicago 
Cheney D, Seyfarth R (2007) Baboon metaphysics: the evolution of a social mind. University of Chicago Press, Chicago

Cheney DL, Seyfarth RM, Fischer J, Beehner JC, Bergman TJ, Johnson SE, Kitchen DM, Palombit RA, Rendall D, Silk JB (2004) Factors affecting reproduction and mortality among baboons in the Okavango Delta, Botswana. Int $\mathrm{J}$ Primatol 25:401-428

Cohen S, Kaplan JR, Cunnick JE, Manuck SB, Rabin BS (1992) Chronic social stress, affiliation, and cellular immune response in nonhuman primates. Psychol Sci 3:301-304

Combes SL, Altmann J (2001) Status change during adulthood: lifehistory by-product or kin selection based on reproductive value? Proc R Soc Lond B Biol Sci 268:1367-1373

Crockford C, Wittig RA, Whitten PL, Seyfarth RA, Cheney DL (2008) Social stressors and coping mechanisms in wild female baboons (Papio hamadryas ursinus). Horm Behav 53:254-265

Ellery WN, Ellery K, McCarthy TS (1993) Plant distribution in an island of the Okavango Delta, Botswana: determinants and feedback interactions. Afr J Ecol 31:118-134

Ender P (2010) How do I compute main effects with ANOVALATOR? UCLA, Academic Technology Services, Statistical Consulting Group. http://www.ats.ucla.edu/stat/stata/ado/analysis/

Engh AL, Beehner JC, Bergman TJ, Whitten PL, Hoffmeier RR, Seyfarth RM, Cheney DL (2006a) Behavioural and hormonal responses to predation in female chacma baboons (Papio hamadryas ursinus). Proc R Soc Lond B Biol Sci 273:707-712

Engh AL, Beehner JC, Bergman TJ, Whitten PL, Hoffmeier RR, Seyfarth RM, Cheney DL (2006b) Female hierarchy instability, male immigration and infanticide increase glucocorticoid levels in female chacma baboons. Anim Behav 71:1227-1237

Engh AL, Hoffmeier RR, Seyfarth RM, Cheney DL (2009) O brother, where art thou? The varying influence of older siblings in rank acquisition by female baboons. Behav Ecol Sociobiol 64:97-104

Frank RE, Silk JB (2009a) Grooming exchange between mothers and non-mothers: the price of natal attraction in wild baboons (Papio anubis). Behaviour 146:889-906

Frank RE, Silk JB (2009b) Impatient traders or contingent reciprocators? Evidence for the extended time-course of grooming exchanges in baboons. Behaviour 146:1123-1135

Fruteau C, Voelkl B, van Damme E, Noe R (2009) Supply and demand determine the market value of food providers in wild vervet monkeys. Proc Natl Acad Sci USA 106:12007-12012

Gomes CM, Mundry R, Boesch C (2009) Long-term reciprocation of grooming in wild West African chimpanzees. Proc R Soc Lond B Biol Sci 276:699-706

Hamilton WJ, Buskirk RE, Buskirk WH (1976) Defense of space and resources by chacma (Papio ursinus) baboon troops in an African desert and swamp. Ecology 57:1264-1272

Henzi SP, Barrett L (2002) Infants as a commodity in a baboon market. Anim Behav 63:915-921

Henzi SP, Barrett L (2007) Coexistence in female-bonded primate groups. Adv Study Behav 37:43-81

Henzi SP, Lusseau D, Weingrill T, van Schaik CP, Barrett L (2009) Cyclicity in the structure of female baboon social networks. Behav Ecol Sociobiol 63:1015-1021

Kaplan JR, Chikazawa DK, Manuck SB (1987) Aspects of fight interference in free-ranging and compound-dwelling rhesus macaques (Macaca mulatta). Am J Primatol 12:287-298

Krause J, Ruxton GD (2002) Living in groups. Oxford University Press, Oxford, UK

Langergraber K, Mitani J, Vigilant L (2009) Kinship and social bonds in female chimpanzees (Pan troglodytes). Am J Primatol 71:840-851

McClintock MK, Conzen SD, Gehlert S, Masi C, Olopade F (2005) Mammary cancer and social interactions: identifying multiple environments that regulate gene expression throughout the life span. J Ger, Ser B 60:32-41

Mitani JC (2009) Male chimpanzees form enduring and equitable social bonds. Anim Behav 77:633-640

Moscovice L, DiFiore A, Crockford C, Kitchen DM, Wittig RM, Seyfarth RM, Cheney DL (2010) Hedging their bets? Male and female chacma baboons form friendships based on likelihood of paternity. Anim Behav 79:1007-1015

Noë R, Hammerstein P (1994) Biological markets: supply and demand determine the effect of partner choice in cooperation, mutualism and mating. Behav Ecol Sociobiol 35:1-11

Palombit RA, Seyfarth RM, Cheney DL (1997) The adaptive value of friendships to female baboons: experimental and observational evidence. Anim Behav 54:599-614

Palombit RA, Cheney DL, Fischer J, Johnson S, Rendall D, Seyfarth RM, Silk JB (2000) Male infanticide and defense of infants in wild chacma baboons. In: van Schaik CP, Janson CH (eds) Infanticide by males and its implications. Cambridge University Press, Cambridge, pp 123-152

Roodt V (1998) Trees and shrubs of the Okavango Delta: nutritional uses and nutritional value. Shell Oil Botswana, Gaborone

Ross K (1987) Okavango: jewel of the Kalahari. Macmillan Publishing Co., New York

Schino G (2007a) Grooming and agonistic support: a meta-analysis of primate reciprocal altruism. Behav Ecol 18:115-120

Schino G (2007b) Grooming, coalitions, and reciprocal altruism in primates. J Anthro Sci 85:235-236

Schino G, Di Giuseppe F, Visalberghi E (2009) Grooming, rank, and agonistic support in tufted capuchin monkeys. Am J Primatol $71: 101-105$

Seyfarth RM (1976) Social relationships among adult female baboons. Anim Behav 24:917-938

Shino G, Aureli F (2007) Grooming reciprocation among female primates: a meta-analysis. Biol Lett 4:9-11

Silk JB (1996) Why do primates reconcile? Evol Anthropol 5:39-42

Silk JB (2007) The strategic dynamics of cooperation in primate groups. Adv Study Behav 37(37):1-41

Silk JB (2009) Nepotistic cooperation in nonhuman primate groups. Phil Trans Roy Soc 364:3243-3254

Silk JB, Cheney DL, Seyfarth RM (1996) The form and function of post-conflict interactions among female baboons. Anim Behav 52:259-268

Silk JB, Seyfarth RM, Cheney DL (1999) The structure of social relationships among female savanna baboons in Moremi Reserve, Botswana. Behaviour 136:670-703

Silk JB, Alberts SC, Altmann J (2003a) Social bonds of female baboons enhance infant survival. Science 302:1231-1234

Silk JB, Rendall D, Cheney DL, Seyfarth RM (2003b) Natal attraction in adult female baboons (Papio cynocephalus ursinus) in the Moremi Reserve, Botswana. Ethology 109:627-644

Silk JB, Alberts SC, Altmann J (2004) Patterns of coalition formation by adult female baboons in Amboseli, Kenya. Anim Behav 67:573-582

Silk JB, Alberts SC, Altmann J (2006a) Social relationships among adult female baboons (Papio cynocephalus). II. Variation in the quality and stability of social bonds. Behav Ecol Sociobiol 61:197-204

Silk JB, Altmann J, Alberts SC (2006b) Social relationships among adult female baboons (Papio cynocephalus). I. Variation in the strength of social bonds. Behav Ecol Sociobiol 61:183-195

Silk JB, Beehner JC, Bergman TJ, Crockford C, Engh AL, Moscovice LR, Wittig RM, Seyfarth RM, Cheney DL (2009) The benefits of social capital: close social bonds among female baboons enhance offspring survival. Proc R Soc Lond B Biol Sci 276:3099-3104 
Smith K, Alberts SC, Altmann J (2003) Wild female baboons bias their social behaviour towards paternal half sisters. Proc Roy Soc Lond B 270:503-510

Vasey PL (1996) Interventions and alliance formation between female Japanese macaques, Macaca fuscata, during homosexual consortships. Anim Behav 52:539-551

Wasser SK, Starling AK (1988) Proximate and ultimate causes of reproductive suppression among female yellow baboons at Mikumi National Park, Tanzania. Amer J Primatol 16:97-121

Weidt A, Hofmann SE, Konig B (2008) Not only mate choice matters: fitness consequences of social partner choice in female house mice. Anim Behav 75:801-808
Wittig RM, Crockford C, Seyfarth RM, Cheney DL (2007) Vocal alliances in chacma baboons (Papio hamadryas ursinus). Behav Ecol Sociobiol 61:899-909

Wittig RA, Crockford C, Lehmann J, Whitten PL, Seyfarth RM, Cheney DL (2008) Focused grooming networks and stress alleviation in wild female baboons. Horm Behav 54:170-177

Yee JR, Cavigelli SA, Delgado B, McClintock MK (2008) Reciprocal affiliation among adolescent rats during a mild group stressor predicts mammary tumors and lifespan. Psychosom Med 70:1050-1059

Zinner D, Groeneveld LF, Keller C, Roos C (2009) Mitochondrial phylogeography of baboons (Papio spp.) - indication for introgressive hybridization? BMC Evol Biol 9:83 